Andrews University

Digital Commons @ Andrews University

Faculty Publications

$9-1-2005$

\title{
HIV Research within the Global Context: Introduction to the Special Issue
}

Clyde B. McCoy

University of Miami

Duane C. McBride

Andrews University, mcbride@andrews.edu

Follow this and additional works at: https://digitalcommons.andrews.edu/pubs

Part of the International Public Health Commons

\section{Recommended Citation}

McCoy, Clyde B. and McBride, Duane C., "HIV Research within the Global Context: Introduction to the Special Issue" (2005). Faculty Publications. 2146.

https://digitalcommons.andrews.edu/pubs/2146

This Conference Proceeding is brought to you for free and open access by Digital Commons @ Andrews University. It has been accepted for inclusion in Faculty Publications by an authorized administrator of Digital Commons @ Andrews University. For more information, please contact repository@andrews.edu. 


\title{
INTRODUCTION
}

\section{HIV Research Within the Global Context: Introduction to the Special Issue}

\author{
Clyde B. McCoy and Duane C. McBride
}

This supplement of the Journal of Urban Health is composed of articles written from presentations at an International Research Conference sponsored by the National Institute on Drug Abuse and the Drug Abuse and AIDS Research Center of the University of Miami School of Medicine. The conference was held in Miami Beach in August of 2004. Although there are many important research themes within each of the articles presented in this volume, there are a few significant underlying public health principles that hold these varied works together.

\section{GLOBAL COOPERATION}

In the past, and perhaps still today, there has been a history of US-based international research that at times was very one-sided. Too often, it was primarily for the career benefit of US-based researchers. Wonderful programs might be initiated, communities impacted, and then the researchers left, often leaving behind feelings of resentment. Over the past few years, this has significantly changed. US-based researchers have come to recognize that international research is based on global cooperation that includes equal partnerships between US-based researchers and international researchers and institutions. This important integrating theme is presented in the first three articles in this issue. The articles by McCoy and his colleagues, Freier and her colleagues, and Page, represent mature reflections on the nature of international research and the interdependence between US researchers and international colleagues. The experience of these scholars reminds researchers of the importance of cultural respect, the recognition of national and local institutions in research host countries, the creation of sustainable research partnerships with international colleagues, and the need to work with local institutions to build capacity to be able to sustain positive intervention efforts. These researchers remind us that without a valid map of the cultural context including relevant institutions, international research cannot succeed, will not be sustained and future research cooperation will be imperiled. These articles provide important suggestions for

Dr. McCoy is with the Drug Abuse and AIDS Research Center, University of Miami, Miami, Florida; and Dr. McBride is with the External Advisory Committee, Drug Abuse and AIDS Research Center, Andrews University, Barrien Springs, Michigan.

Correspondence: Clyde B. McCoy, PhD, Professor and Chair, Department of Public Health and Epidemiology, Director, Comprehensive Drug Research Center (CDRC), University of Miami, 1801 NW 9th Avenue, Suite 300, Miami, FL 33136. (E-mail: cmccoy@med.miami.edu) 
strategies that significantly improve the probability of successful and sustainable international research.

\section{POPULATION-BASED INTERVENTIONS}

It has been said that as an institution and a set of activities, public health is one of the best untold studies in the world. Epidemics prevented by clean water, sewage disposal, vaccinations, or health education rarely make headlines. US society usually focuses on access to acute health care, and particularly, the high proportion of uninsured individuals which often results in either lack of adequate health care or the over use of expensive facilities such as emergency rooms. Within US culture, there is a strong emphasis on the individual and changing behavior one individual at a time, often without understanding or using community context. The basic health access structure of US society focuses on the individual. Individuals are insured not communities. In many of the articles presented in this special issue, notably the articles led by Greenberg, Hammett, Miguez-Burbana, Strathdee, Surratt, and Zhao, researchers provide strong arguments for a population-based approach to HIV-risk prevention. Health education works; high-risk behaviors change and the changes can be sustained. Within that framework, these articles stress the role of communities and a variety of institutions in every country that are or can be used to reduce, in a sustainable manner, HIV-risk behavior. Sustainable at-risk population change only occurs within a national and community cultural and institutional context. Successful programs are based on identifying high risk populations and drawing on community and institutional contexts to change group behavior and sustain that change.

\section{A GLOBAL SOCIAL NETWORK}

In a strong sense, HIV has reminded us that we live in a world characterized by global interaction and that HIV epidemics and endemics can only be addressed recognizing and intervening with at-risk networks. HIV is spread by intimate human interaction. The article by Jones and colleagues reminds us of the crucial role of partners in sustaining changes in HIV-risk behavior. The article by Gyarmathy and Neaigus recognizes that local networks overlap with broader social networks that in turn overlap with international networks. Social networks were a major part of HIV transmission from local communities to international venues. This article helps us understand how different types of networks function to spread HIV, and how intervening in social networks is crucial to reducing HIV transmission.

\section{HIV PREVENTION AND SOCIAL JUSTICE}

Many studies also inform us that those at risk for HIV infection also have significant other educational, health, and economic access needs. The article by Sherman and colleagues particularly focuses on the broad social context of HIV-risk behavior. Engaging in HIV-risk behavior often occurs because of or at least within the context of almost overwhelming educational, economic, and shelter problems. Sherman and her colleagues document that the context of street children and their HIV-risk behaviors very much involves immediate survival issues. Without access to those things that provide the most basic survival, including food and housing, HIV-risk behaviors are not likely to change. This article recognizes that improving the public 
health takes place within the framework of improving broad aspects of a society that includes economic, health and educational systems as well as social attitudes that marginalizes members of the society. Individual or even population-based attempts to change HIV-risk behavior may fail because these behaviors occur within an immediate survival context when a society fails to provide basic access to food, housing, education, and economic opportunities. HIV prevention involves social and economic justice as much as specific health education and intervention programs.

Overall, these articles provide an important overview of international research on HIV-risk behaviors. They show a high level of international interest and successful cooperative interaction among diverse researchers. All of the articles reinforce the importance of cultural competence from the individual to the community/institutional and national levels. This competence is essential if successful projects are to be designed and implemented and sustained. The articles presented show a clear recognition of the need for institutional transfer from a programmatic intervention to a sustainable local institution. Finally, and perhaps most importantly, there is a recognition of the broad and deep context of HIV-risk behaviors. At a fundamental level, only broad economic, social, and political change that integrates disvalued members of a society into the culture and provides educational and economic opportunities will result in significant global reductions of HIV-risk behavior and infection.

\section{ACKNOWLEDGEMENT}

This special issue is a product sponsored by the Drug Abuse and AIDS Research Center (DAARC) at the University of Miami funded by National Institutes of Health/National Institute on Drug Abuse. Those who have contributed to its success other than the authors and co-authors are mentioned below in acknowledgement of their efforts, commitment, and support.

Project Officer, NIDA: Dionne Jones, PhD. DAARC Core Leaders: Clyde B. McCoy, PhD; Dale D. Chitwood, PhD; Lee Crandall, PhD; Lisa B. Metsch, PhD; J. Bryan Page, PHD. External Advisory Board: Duane McBride (Chair), PhD; Hector Colon, PhD; Sam Friedman, PhD; Tom Liberti; Ron Stall, PhD; Sally Stevens, PhD; Stephanie Strathdee, PhD; Robert Trotter, PhD. Project Coordinators and Editors: Sarah Messiah, MPH; Mary Comerford, MSPH. 